\title{
DE CHAPINGO A SONORA: \\ PANDURANG KHANKHOJE EN MÉXICO \\ Y EL TRÁNSITO DEL AGRARISMO \\ A LA AGROINDUSTRIA
}

\author{
Daniel Kent Carrasco \\ Centro de Investigación y Docencia Económicas
}

$\mathrm{E}_{\text {nario Pandurang Khankhoje por el México posrevoluciona- }}^{\text {ste artículo se centra en el paso del agrónomo y revolucio- }}$ rio. Pandurang Khankhoje (1884-1967) es una figura singular y fascinante de la historia global del pasado siglo xx. Nacido en Wardha, en la región de Maharashtra en la India británica, Khankhoje abandonó la India en 1905, a la edad de 21 años y durante el siguiente medio siglo llevó una vida itinerante entre Asia, Norteamérica y Europa. A lo largo de su vida pasó largos periodos en India, Japón, Persia, Estados Unidos, Alemania y México. Su paso por distintos rincones del globo lo vinculó con variadas corrientes de transformación política, ideológica y científica que tuvieron lugar en la primera mitad del siglo xx. Fue activista anticolonial, organizador sindical, estudiante de posgrado, genetista de vanguardia, pedagogo agrarista y empleado de la agroindustria. A pesar de haber permanecido siendo siempre un ferviente nacionalista indio y defensor de la causa anticolonial, durante una parte importante de su vida, Khankhoje fue un ciudadano naturalizado mexicano. Si bien durante su

Fecha de recepción: 7 de junio de 2019

Fecha de aceptación: 28 de agosto de 2019 
juventud defendió las causas del anticolonialismo, el anarcosindicalismo y el agrarismo revolucionario, durante su edad madura actuó como agente del capital privado y funcionario de importantes compañías transnacionales. Durante su estancia de tres décadas en México (1924-1954), Khankhoje transitó de ser un súbdito indio del Imperio británico a ser un ciudadano naturalizado, y de ser un fugitivo desempleado a convertirse en un reconocido científico. Su estancia en el país transcurrió entre el momento de consolidación del régimen posrevolucionario y el surgimiento del llamado "milagro mexicano". En este breve texto, que forma parte de una investigación más amplia en torno de su vida itinerante y los contactos entre India y México a lo largo del siglo xx, y que se deriva de la investigación realizada para mi disertación doctoral sobre la historia política e intelectual del anticolonialismo y el nacionalismo indio entre la primera guerra mundial y la segunda posguerra, ${ }^{1}$ me interesa argumentar que el estudio de la estancia de Pandurang Khankhoje en el país brinda importantes pistas para entender el tránsito ideológico, institucional y científico que acercó las trayectorias del agrarismo y la agroindustria durante aquellos años, prefigurando así el inicio en México de la llamada revolución verde.

Como resultado de su periplo ideológico, personal y geográfico, y a pesar de su importante contribución científica, Pandurang Khankhoje ha permanecido como un personaje poco conocido, una mera curiosidad anecdótica, en los recuentos históricos tanto de México como de India. Su rastro emerge en textos y estudios pertenecientes a distintas ramas y campos historiográficos. Como resultado de su inicial paso por Norteamérica entre 1906 y 1914, Khankhoje ha sido recuperado por autores interesados en el estudio del entorno anarcosindicalista radical de la costa oeste de Estados Unidos

${ }^{1}$ Kent Carrasco, “Jayaprakash Narayan”. 
y Canadá durante las primeras décadas del siglo $\mathrm{xx}^{2} \mathrm{y}$ ocupa un lugar importante, aunque menor, en la más reciente historiografía sobre el movimiento nacionalista anticolonial Ghadar. ${ }^{3}$ En el campo de la historia de las disciplinas científicas en México, el indio itinerante tiene apariciones fugaces, aunque significativas, en importantes estudios sobre la historia de la institucionalización de la genética y la historia de la agronomía en el México posrevolucionario. ${ }^{4}$ Recientemente, y desde una perspectiva teórica, se ha recurrido a la figura de Khankhoje y su paso por México para impulsar un ejercicio de "dislocación" de estructuras narrativas y simbólicas heredadas con miras a revitalizar y descentrar el estudio de la historia global de la ciencia. ${ }^{5}$ El único libro en el que se tiene una narrativa sistemática de su vida y su paso por México es el volumen de memorias preparado y redactado por su hija Savitri, el cual adolece de las limitaciones y sesgos característicos de la escritura biográfica. ${ }^{6}$ Tomando estos trabajos como punto de partida, este artículo se plantea ofrecer una visión más profunda de su vida y trayectoria a la luz de hallazgos empíricos originales, para contribuir al estudio del papel de la investigación científica agronómica en el cambio agrario durante el siglo xx. Al mismo tiempo, este texto entrará en discusión con la producción historiográfica que, desde hace algunos años, se ha enfocado en el proyecto de modernización de la ciencia y política de la producción agrícola en México durante la primera mitad del siglo xx y los procesos que desembocaron en la revolución verde. Este campo ha abordado la relación entre

2 Zimmer, Immigrants against the State y Kent Carrasco, "The Breath of Revolution".

3 Ramnath, Haj to Utopia.

${ }^{4}$ Barahona Echeverría, Pinar y Ayala, La genética en México y Cotter, Troubled Harvest.

5 Soto Laveaga, Largo dislocare.

${ }^{6}$ Sawhney, I Shall Never Ask for Pardon. 
el Estado y el capital privado en el uso de los recursos hidráulicos y la transformación del paisaje desértico del norte de México, ${ }^{7}$ el cambio tecnológico en el agro norteño, ${ }^{8}$ las "revoluciones ambientales" que resultaron de la transformación técnica y económica de la producción agrícola, ${ }^{9}$ la trayectoria de la educación científica y de la institucionalización de la ciencias agrícolas en México, ${ }^{10}$ y los procesos institucionales que desembocaron en la creación de la Oficina de Estudios Especiales, el Centro Internacional de Mejoramiento del Maíz y el Trigo, la exportación de técnicas de mejoramiento de cosechas desarrolladas en México a otros países del otrora llamado Tercer Mundo, ${ }^{11}$ y las dinámicas internacionales de flujo e intercambio de ideas, recursos, tecnologías y personas en los procesos de reconfección del sector agrícola en México y Estados Unidos. ${ }^{12}$

A partir de esto, y más allá de su relevancia para la historia política del México posrevolucionario, en este artículo se busca utilizar la historia de Khankhoje para vincular la historia del cambio agrario en México durante la primera mitad del siglo xx con los procesos de transformación industrial de la agricultura y el desarrollo de las ciencias agrícolas y la agronomía a nivel global. ${ }^{13}$ La primera sección abordará la estancia de Khankhoje

\footnotetext{
7 Cerutti, "La agriculturización del desierto".

8 Rivas Sada, "Cambio tecnológico".

9 Boyer y Cariño, "Mexico's Environmental Revolutions” y Sonnenfeld, "Mexico's 'green revolution"”.

10 Olea Franco, "One century".

11 Gutiérrez NúÑ̃ez, “Cambio agrario y Revolución Verde” y Méndez RojAs, "El Programa Cooperativo".

12 Olsson, Agrarian Crossings.

$13 \mathrm{Al}$ margen de los debates entre los defensores de la historia "global" y la "internacional", puesto que hasta 1930 Khankhoje fue legalmente un súbdito indio del Imperio británico y su carrera política inició en el seno de un movimiento transcontinental en defensa de un nacionalismo inexistente, la etiqueta de global me parece más exacta para referirme a su trayectoria.
} 
en Estados Unidos y Europa entre 1906 y 1924, con el fin de contextualizar y ofrecer varias claves de su posterior adaptación al México posrevolucionario. La segunda sección analiza los primeros años de Khankhoje en México (1924-1936), y se enfoca en su paso como profesor por la Escuela Nacional de Agricultura, su participación en círculos agraristas de la época, su relación con figuras como Marte R. Gómez y Úrsulo Galván, y su contribución como científico al establecimiento del proyecto modernizador del cardenismo. La tercera sección aborda brevemente el proceso de naturalización de Khankhoje entre 1925 y 1930. La cuarta analiza su paso del agrarismo a la agroindustria entre 1936 y finales de la década de 1940, y las maneras en las que durante estos años Khankhoje sirvió como vínculo entre las iniciativas del gobierno federal y de distintos estados y la consolidación del capital privado en la producción agrícola, sobre todo en la región del Noroeste. Finalmente, en un breve epílogo propongo que la historia de Khankhoje en México puede ser leída como una "pre-historia" de la revolución verde, basándome en los nexos de su actividad científica y política durante las décadas de 1920, 1930 y 1940 con el surgimiento de las actividades de la Oficina de Estudios Especiales (1943) y, en años posteriores, el Centro Internacional para el Mejoramiento del Maíz y el Trigo en México. Basaré mi argumentación en el estudio de documentos localizados en los P. S. Khankhoje Papers, de la Biblioteca Nacional Jawaharlal Nehru en Delhi, India, documentos del Archivo Histórico Genaro Estrada de la Secretaría de Relaciones Exteriores de México, el Archivo Digital del Sur de Asia y América (SAADA) y en la información recabada en una entrevista con Ana Savitri Sawhney Khankhoje, hija de Pandurang. ${ }^{14}$

${ }^{14}$ Agradezco a Ana Savitri Sawhney Khankhoje la gentileza de aceptar compartir conmigo sus recuerdos e impresiones sobre la vida de su padre y su familia en México. 
Pandurang Khankhoje dejó la India británica a principios de 1906 y llegó a Estados Unidos tras haber pasado una corta temporada en Japón. ${ }^{15}$ El joven, nacido en 1884, había estado involucrado en actividades de grupos nacionalistas anticoloniales en su región natal de Maharashtra durante los primeros años del siglo. Su devoción política se forjó durante un periodo de creciente agitación antibritánica que culminaría con el estallido del movimiento swadeshi en 1905, un amplio impulso insurreccional que promovió la acción directa y masiva en rechazo de las instituciones y símbolos del poder imperial británico, el boicot al estado colonial y la creación de nuevas formas de organización y protesta. ${ }^{16} \mathrm{La}$ insistencia en la autonomía técnica, económica y simbólica de la India frente al poder colonial británico era de central importancia para la práctica y la retórica de protesta del movimiento swadeshi. En aquellos años, Japón, cuya marina acababa de vencer a las fuerzas rusas en la guerra de 1905, era visto por activistas e ideólogos alrededor del mundo colonial como el ejemplo innegable de que los pueblos de Asia eran capaces de hacer frente a las potencias europeas. Numerosos jóvenes nacionalistas alrededor de Asia veían al país nipón como la meca del anticolonialismo y el centro de la marea creciente del panasianismo, una corriente de pensamiento que abogaba por el retorno a modelos civilizatorios, técnicos e ideológicos no occidentales como la condición básica para impulsar la liberación de los pueblos oprimidos

15 Copia de constancia emitida por K. L. F. Armitage, comisionado del distrito de Wardha, en torno a la solicitud de Sadashiv Venkatesh Khankhoje, escribano, para la emisión de un pasaporte el 29 de mayo de 1924, JNML, PSK, S.F. 1, ff. 14-15.

${ }_{16}$ Respecto del movimiento swadeshi, véase SARKar, The Swadeshi Movement y GuHA, Dominance Without Hegemony. 
del continente. ${ }^{17}$ Obligado a huir de India para evitar el encarcelamiento, en un inicio el joven Khankhoje planeaba viajar a Japón, recibir entrenamiento militar y nutrirse de la creciente marea del panasianismo. Sin embargo, el fugitivo indio tan solo pasó unas cuantas semanas en la tierra del sol naciente y partió poco después hacia Estados Unidos. Desembarcó en San Francisco en abril de 1906. ${ }^{18}$

Durante los primeros años del siglo xx, Estados Unidos recibió una importante migración del sur de Asia formada por un creciente número de trabajadores agrícolas, la mayoría campesinos de la región norteña del Punjab y jóvenes que buscaban la oportunidad de estudiar. A diferencia de Gran Bretaña, donde se formó gran parte de la élite liberal india del siglo xIx, incluyendo a figuras como Jawaharlal Nehru o M. K. Gandhi, Estados Unidos ofrecía a los estudiantes pobres la posibilidad de trabajar para mantenerse económicamente al tiempo que estudiaban. Miles de jóvenes, como Khankhoje, viajaron a Estados Unidos animados por mensajes como los contenidos en una gaceta estudiantil de la época donde se afirmaba que para "muchos de nuestros estudiantes [indios] en América” era posible pagarse los estudios en universidades de gran prestigio, como Yale o Harvard, siempre y cuando los estudiantes estuvieran dispuestos "a desechar el orgullo de casta" y "perseverar en el servicio de la patria". ${ }^{19} \mathrm{Al}$ mismo tiempo, educarse en Estados Unidos era visto por estudiantes indios de inclinaciones anticoloniales como una manera de obtener una formación académica de primer nivel y, al mismo tiempo, escapar a los circuitos de control $\mathrm{y}$ vigilancia ejercidos por el poder colonial sobre los estudiantes indios en el Reino Unido. A diferencia de sus paisanos en

17 Respecto del panasianismo y la creciente importancia simbólica de Japón entre los círculos nacionalistas en Asia durante los primeros años del siglo xx, véase Mishra, De las ruinas.

18 Sawhney, I Shall Never Ask for Pardon, pp. 11-30.

19 Roy, "Self-support in American Universities", pp. 9-11. 
Oxford o Cambridge, que generalmente optaban por formarse como abogados con miras a insertarse en las estructuras administrativas del Estado colonial británico, los estudiantes indios en Estados Unidos, como Khankhoje, tenían una marcada preferencia por la educación técnica que, esperaban, les permitiría contribuir a la autonomía económica y tecnológica de la futura India independiente. ${ }^{20}$

Durante su estancia en Estados Unidos (1906-1914), Khankhoje participó en dos movimientos revolucionarios contrapuestos. Por un lado, como activista político formó parte de la importante movilización nacionalista conformada alrededor del legendario periódico Ghadar, que reunió a un ecléctico grupo de radicales defensores del anarcosindicalismo, el socialismo internacionalista, el nacionalismo romántico al estilo del italiano Giuseppe Mazzini y el antiimperialismo militante. ${ }^{21}$ Por otro lado, como estudiante de ciencias agrícolas Khankhoje se formó en un periodo de profunda transformación de la disciplina, en la que se comenzaron a sentar las bases de las innovaciones científicas, técnicas y comerciales que en décadas posteriores darían paso a la explosión de la agroindustria y el inicio de la revolución verde. Como veremos, en la trayectoria de Khankhoje ambas corrientes se unieron mediante la conjunción del rechazo de la explotación económica que guió a buena parte de la izquierda internacional a partir de la segunda mitad del siglo xIx y el ideal modernista de supeditar el progreso tecnológico y científico a la creación de un orden social más justo y equitativo.

Tras su llegada a California, Khankhoje se sumergió en el vibrante y cosmopolita ambiente radical de izquierda que durante las primeras décadas del siglo xx dominaba el escenario político

20 Sobre la importancia de la educación técnica entre los jóvenes indios formados durante la época del movimiento swadeshi, véase ManjaPra, "Knowledgeable Internationalism and the Swadeshi Movement".

${ }^{21}$ Sobre la historia de Ghadar, véase Ramnath, Haj to Utopia. 
de la costa oeste estadounidense. En los campos agrícolas de Oregon, el recién llegado se topó con los organizadores de la International Workers of the World, o wobblies, un sindicato internacionalista por medio del cual recibió su "primera introducción al pensamiento socialista". ${ }^{22}$ A los pocos años de establecerse en Estados Unidos, Khankhoje participó en la creación de la Liga por la Independencia India y la Asociación Hindi de la Costa Pacífica, organizaciones que reunieron a un importante sector de trabajadores indios de la costa oeste; más tarde actuaría como el segundo al mando del Partido Ghadar creado en noviembre de 1913. Mediante su participación en Ghadar, Khankhoje entró en contacto con miembros del Partido Liberal Mexicano, encabezado por los hermanos Flores Magón, y con personajes asociados con la publicación de su periódico Regeneración. Para radicales de distintas nacionalidades, los abruptos cambios que tenían lugar en México representaban una movilización contra el imperialismo capitalista y en defensa de la solidaridad de clase. ${ }^{23}$ Acontecimientos como la huelga de Cananea de 1906 y la toma de Mexicali de 1911 circulaban entre círculos socialistas y anarcosindicalistas de la región por medio de escritos de periodistas famosos como John Kenneth Turner o Ethel Duffy que pintaban una imagen de México como una tierra azotada por el fervor revolucionario contra la injusticia y la explotación. ${ }^{24}$ A los ojos de muchos activistas no blancos de la costa oeste, las actividades de los Flores Magón eran un importante referente dentro de la esfera anarcosindicalista, y a los ojos del joven nacionalista indio los líderes del Partido Liberal Mexicano aparecían como la vanguardia de la virtuosa

22 Sawhney, I Shall Never Ask for Pardon, p. 83.

23 SPEnSer, Stumbling Its Way Through Mexico, p. 2.

${ }^{24}$ Sobre el entusiasmo generado por la revolución mexicana entre círculos internacionalistas de principios del siglo xx en California, véase Heatherton, "The Color Line". 
lucha del pueblo mexicano "en contra de los ricos y opresores terratenientes". ${ }^{25}$

Al margen de su compromiso político, en Estados Unidos Khankhoje también encontró el tiempo para estudiar y formarse como científico. En 1908 se matriculó en la escuela de agricultura de la Universidad de Berkeley, y en 1913 obtuvo un título de Bachelor of Science en la misma disciplina por el State College of Washington. ${ }^{26}$ En sus memorias, Khankhoje declara que tomó la decisión de convertirse en agrónomo impulsado por el nacionalista chino Sun Yat-Sen, a quien el indio conoció durante su breve paso por Japón. Al convertirse en agrónomo, y aun en caso de que no pudiera presenciar la independencia de la India, Khankhoje imaginaba que sería capaz de ayudar a su pueblo a evitar las desastrosas hambrunas artificiales creadas por el colonialismo británico en la India. ${ }^{27}$ La preocupación por el hambre y el "drenado de la riqueza" de India por parte de los británicos había sido uno de los puntos centrales de la retórica nacionalista anticolonial durante la segunda mitad del siglo XIX..$^{28}$ La tesis del "drenado de riqueza" (drain of wealth) fue plasmada de manera elocuente por el nacionalista indio Dadabhai Naoroji, originario de la misma región que Khankhoje, quien en 1870 comparó la pauperización de India con el proceso de extracción de riqueza desde Gran Bretaña hacia Italia en el siglo xiv. Mediante la combinación de datos empíricos y poderosas metáforas de "vampirismo económico", "la India sangrante" y la "economía canibalesca" del Imperio, Naoroji desarrolló una devastadora crítica del colonialismo que circuló ampliamente no sólo en

\footnotetext{
25 Sawhney, I Shall Never Ask for Pardon, p. 72. Los vínculos de colaboración e intercambio establecidos entre activistas indios y mexicanos en la costa oeste de Estados Unidos durante las décadas inaugurales del siglo xx son examinados con más detenimiento en Kent Carrasco, "The Breath of Revolution".

${ }^{26}$ JNMMJ, PSK, S.F. 4, f. 8.

27 Sawhney, I Shall Never Ask for Pardon, p. 56.

28 Véase NaOroji, Poverty of India.
} 
India sino en periódicos de Europa y el Reino Unido y que sería citada en el volumen 3 de El capital de Marx, pasando a la historia como una de las condenas del colonialismo más importantes del siglo XIX. ${ }^{29}$ En este sentido, y puesto que Khankhoje no provenía de una casta de agricultores o trabajadores del campo -su padre era un escriba notarial en Wardha-, podemos suponer que en la raíz de su preocupación por la labor agrícola había motivaciones ideológicas y políticas relacionadas a su afán revolucionario. Al margen de las razones que lo condujeron al estudio de la agronomía, Khankhoje pronto demostró tener aptitudes para la labor científica. En enero de 1914, y al poco tiempo de graduarse del State College of Washington, el indio publicó su primer texto académico sobre los factores que afectaban los requerimientos de agua de ciertos cultivos comerciales. Este trabajo, resultado de una investigación desarrollada en la estación experimental de Pullman, estado de Washington, apareció en el Journal of the American Society of Agriculture. ${ }^{30} \mathrm{~A}$ principios de aquel año, el agrónomo comenzó un programa de doctorado en la Universidad de Minnesota, como parte del cual inició una serie de trabajos en las estaciones experimentales de la ciudad de Saint Paul. ${ }^{31}$

Por medio de su publicación, y quizá sin saberlo, el joven científico estaba participando de una revolución de alcances mucho mayores que aquella por la que luchaban sus camaradas del partido Ghadar. La formación científica y académica de Khankhoje en Estados Unidos tuvo lugar en un momento de dramática transformación del estudio y la aplicación de las ciencias agrícolas. Tras un periodo de crisis agrícola nacional en los últimos años del siglo xIX, distintas universidades en

\footnotetext{
29 Para un análisis de la vida política de estas ideas y su impacto en el movimiento nacionalista indio y el anticolonialismo europeo del siglo xIx, véase Goswami, Producing India, p. 227.

30 Khankhoje, "Some factors".

31 Sawhney, I Shall Never Ask for Pardon, pp. 114-115.
} 
Estados Unidos se unieron en un esfuerzo conjunto por modernizar los métodos de cultivo y optimizar la producción del campo siguiendo los principios de la eficiencia económica y la exactitud técnica. Durante la década de 1900, instituciones como el State College of Washington, la Universidad de Minnesota y la Universidad de Cornell desarrollaron líneas de investigación e innovación científicas entre las que destacan la creación de nuevas técnicas de irrigación, fertilización química, acondicionamiento de suelos estériles y el desarrollo de nuevas técnicas de mejoramiento de semillas, para contribuir a que la agricultura se convirtiera en una actividad industrial altamente redituable. ${ }^{32}$ Desde el gobierno, este esfuerzo se complementó con un importante aumento de los fondos destinados a la investigación agrícola, la creación de nuevos espacios de investigación, y el establecimiento de numerosas estaciones y campos experimentales a lo largo del país. ${ }^{33}$ Es probable que durante sus primeros meses en la Universidad de Minnesota, Khankhoje haya tenido su primer contacto con el trabajo experimental agrícola en México, pues en marzo de 1914 el agrónomo estadounidense C. H. Bailey, de aquella casa de estudios, publicó un estudio en el mismo Journal of the American Society of Agriculture en torno de la siembra de diversas variedades de trigo en las inmediaciones de Hermosillo, Sonora. ${ }^{34} \mathrm{Al}$ mismo tiempo, estas transformaciones y nuevas líneas de investigación tuvieron eco al sur de la frontera, ya que durante los primeros años del siglo los agrónomos porfiristas gradualmente abandonaron su fijación con la ciencia

\footnotetext{
32 Perkins, Geopolitics and the Green Revolution, pp. 75-101.

33 Entre 1906 y 1914 el número de estaciones experimentales en Estados Unidos pasó de 950 a 1853 , mientras que los fondos públicos otorgados para la experimentación agrícola creció de 2 a 5 millones de dólares. True, $A$ History of Agricultural Experimentation, p. 171, citado en PERKINs, Geopolitics and the Green Revolution pp. 84-85.

34 BaILey, "The composition and quality of Mexican wheats".
} 
y la tecnología importadas de Francia para abrirse a los avances provenientes de Estados Unidos. ${ }^{35}$

En 1914, con el inicio de la guerra en Europa, la situación de los migrantes indios en Estados Unidos, en especial aquellos involucrados en actividades antibritánicas, se volvió más delicada y riesgosa. El joven Khankhoje se vio obligado a abandonar su doctorado al poco tiempo de haberlo comenzado debido al aumento de la represión de grupos y figuras relacionadas con las actividades del Ghadar. En abril de aquel año, el principal líder del partido, Lala Har Dayal, huyó a Suiza después de que se girara una orden de aprehensión en su contra y en los meses siguientes se gestó una ola de represión contra nacionalistas indios involucrados en las actividades antibritánicas del Imperio alemán que culminaría con el muy publicitado juicio de la "conspiración indo-alemana" ${ }^{36}$ A mediados de 1914, Khankhoje huyó de Saint Paul con dirección a Nueva York, desde donde zarpó hacia Europa. En septiembre de 1914, desembarcó en Constantinopla. Durante los años de la guerra, Khankhoje se estableció en Fars, al sur de Persia, donde contribuyó a distintas actividades pedagógicas y científicas ${ }^{37}$ y en 1921 se asentó en Berlín con la ayuda de la comunidad de exiliados indios de la ciudad. En sus memorias, Khankhoje afirma que durante los primeros años de la primera posguerra siguió involucrado en diversos circuitos de actividad política, incluido el activismo de

\footnotetext{
${ }^{35}$ CotTer, Troubled Harvest, pp. 19-47.

36 "Contra la deportación de Har Dayal", en Regeneración (18 abr. 1914). Sobre la creciente represión contra grupos anarcosindicalistas y radicales durante los primeros años de la primera guerra mundial, véase ZIMMER, Immigrants against the State, pp. 136-165. Para un recuento de la "conspiración indoalemana" véase Fraser, "Germany and Indian Revolution" y Plowman, "The British Intelligence Station".

37 Documentos firmados por Su Excelencia, el Ameer del Estado de Ghanshghai, Fars-Persia, Ameer'Ashayer, Ghashghai Aspas, 3 de noviembre 1921, JNMML, $P S K, S F, 2$, f. 9 y 11.
} 
la recién creada Internacional Comunista. ${ }^{38}$ Sin embargo, y de acuerdo con los recuerdos de su hija Savitri, sus años en Berlín fueron un periodo oscuro en la vida de Pandurang, marcado por el hambre y el miedo constante de un atentado contra su vida por parte del gobierno británico. ${ }^{39}$ Finalmente, en enero de 1924, tras casi 10 años de ausencia, el indio trashumante partió de regreso hacia Estados Unidos con dirección a México.

\section{UN AGRARISTA INDIO EN EL MÉXICO \\ POSREVOLUCIONARIO (1924-1936)}

De acuerdo con sus memorias, el interés de Khankhoje por México se gestó durante los primeros años de su estancia en Estados Unidos. En un inicio, lo asombró el sorprendente parecido fenotípico entre sus paisanos indios y los mexicanos que conoció en los campos agrícolas de California y Oregon. En sus memorias, Khankhoje señaló que, a diferencia de otros "asiáticos", aquellos mexicanos "se veían igual que yo" 40 y ocupaban un lugar similar en la categorización racial de la época. Después de cultivar la amistad de trabajadores y activistas mexicanos, Khankhoje compartió el enorme entusiasmo generado por la toma de Mexicali encabezada por fuerzas magonistas en 1911, que incensó a muchos anarcosindicalistas al norte del río Bravo. Encandilado con la idea de unirse a la revuelta armada, el joven migrante cruzó la frontera desde Caléxico solo para volver al norte desanimado por la situación en México: "la revolución era mucho más violenta de lo que había imaginado [y] hordas de

\footnotetext{
38 Sawhney, I Shall Never Ask for Pardon, pp. 199-225.

39 Entrevista con Savitri Ana Sawhney Khankhoje, realizada el 15 de abril de 2019.

40 Sawhney, I Shall Never Ask for Pardon, p. 63. En Xalapa había funcionado, desde 1920, el centro de actividades del Partido Comunista. Véase Falcón, El agrarismo, p. 133.
} 
bandidos rondaban los caminos y el campo". ${ }^{41}$ Los motivos que guiaron su decisión de viajar a México más de diez años después de esta inicial desilusión revolucionaria no están claros. Sin embargo, no era el primer indio que, por medio de Estados Unidos, buscaba refugio en México en aquellos años: en 1917 el famoso Manabendra Nath Roy había llegado a la ciudad de México, donde luego participaría en la creación del Partido Comunista Mexicano, ${ }^{42}$ y en los últimos años de la década de 1910 otro miembro de Ghadar, Heramba Lal Gupta, publicó en la capital una traducción de una obra de Rabindranath Tagore. ${ }^{43}$

Independientemente de las razones que lo llevaron a elegir México como su destino, en 1924 el agrónomo itinerante pronto se sirvió de sus habilidades científicas para hacerse un lugar en el cambiante escenario posrevolucionario del país. El joven migrante se benefició del abanico de oportunidades científicas y laborales que se abrió para los agrónomos en el México de la década de 1920. Como ha mostrado Joseph Cotter en su fascinante estudio del gremio, durante aquellos años la profesión agronómica se fundió con el programa agrarista del nuevo régimen posrevolucionario, lo que permitió a sus practicantes el acceso a puestos gubernamentales, académicos y técnicos de importancia. ${ }^{44}$ Por medio de los buenos oficios de Ramón P. Denegri, a quien había conocido durante su estancia como cónsul mexicano en San Francisco entre 1913 y 1915, Khankhoje fue contratado como profesor en la Escuela Nacional de Agricultura (ENA) en

\footnotetext{
${ }^{41}$ Sawhney, I Shall Never Ask for Pardon, pp. 93-94.

42 Kent Carrasco, "M. N. Roy en México".

${ }^{43}$ Chitra. Como es sabido, Roy dejó México en 1919 y pasó a convertirse en una importante figura de la historia internacional de la izquierda del siglo xx. Por otro lado, Heramba Lal Gupta permaneció en México hasta su muerte, en 1951. Sobre Roy en México, véase Goebel, "Una biografía entre espacios", y Kent Carrasco, "M. N. Roy en México".

${ }^{44}$ Cotter, Tronbled Harvest, pp. 49-80.
} 
mayo de $1924 .{ }^{45}$ Denegri, quien ostentaba el cargo de secretario de Agricultura y Fomento en el gobierno de Álvaro Obregón, también encabezaba la Comisión de la Reforma Agraria y había dirigido la mudanza de la Escuela Nacional de Agricultura desde su sede original en el convento de San Jacinto hacia Texcoco en el Estado de México. Instalada en la exhacienda de Chapingo, la materialización del injusto orden socioeconómico que la Revolución había repudiado, la Escuela pronto se erigió como un importante símbolo del proyecto de reforma y modernización agraria encabezado por el régimen posrevolucionario, en el que se unían la "voz de protesta" pronunciada por los "hermanos Flores Magón” y el anhelo de los campesinos zapatistas que habían enarbolado el canto de guerra de "tierra y libertad". 46

En Chapingo, Khankhoje se convirtió en el primer profesor en impartir clases de genética en México ${ }^{47}$ y se involucró en las actividades de los nuevos campos experimentales impulsados por el director de la escuela Marte R. Gómez, colaborador cercano de Denegri y ferviente defensor de los ideales agraristas de la Revolución. Para el ingeniero Gómez, la modernización de la agricultura representaba la única manera de consolidar la reforma agraria impulsada por la Revolución y de hacer "coincidir el camino de la libertad" y la justicia con el "camino del progreso". ${ }^{48}$ En los campos experimentales de Texcoco, Khankhoje encabezó lo que quizá fuera el primer esfuerzo institucional por realizar experimentos de mejoramiento genético de variedades agrícolas en México. Con el apoyo del director de la ENA y del ministro de Agricultura y Fomento, el científico indio aplicó los conocimientos que había adquirido durante su formación en Estados Unidos para desarrollar nuevas semillas de maíz "resistentes a

45 Oficio número 91992 de la Oficialía Mayor, Departamento de Administración, Sección de Personal, 11 de mayo, 1924, JNMML, PSK, SF, 2, f. 24.

46 Gómez, Historia de la Comisión, pp. 21-23.

47 Barahona Echeverría, Pinar y Ayala, La genética en México, p. 135.

48 Gómez, La Reforma Agraria de México, p. 123. 
las enfermedades, las heladas y las sequías" del altiplano mexicano. ${ }^{49}$ En 1925, Waldo Soberón, quien reemplazó a Gómez como director de la ENA a principios de ese año, celebró los exitosos experimentos de Khankhoje y promovió la donación de otras 25 ha para impulsar la labor de mejoramiento agrícola encabezada por el indio. ${ }^{50}$ No es difícil entender el atractivo de la figura de Khankhoje para personajes como De Negri, Soberón y Gómez: el indio encarnaba la forja perfecta del conocimiento científico de punta con la devoción revolucionaria antiimperialista. Como ha señalado Gabriela Soto Laveaga, en el México de la década de 1920, el sentimiento antibritánico de Khankhoje embonaba a la perfección con el celo revolucionario antiimperialista de los impulsores de la Escuela Nacional de Agricultura y su defensa de la ingeniería social revolucionaria en pos de un nuevo campesino, que iba de la mano con la redefinición del papel de la ciencia en los campos agrícolas. ${ }^{51}$

Además de dar a conocer su trabajo entre importantes figuras del agrarismo gubernamental de la época, Khankhoje también aprovechó su estancia inicial en Chapingo para establecer lazos con el entorno comunista de la ciudad de México. Durante sus primeros meses en la ENA, el científico coincidió con el pintor Diego Rivera, quien por aquel entonces estaba dando inicio a su trabajo muralista en la Capilla Riveriana (1924-1928). Por medio de Rivera, Khankhoje entabló relaciones con el cosmopolita

\footnotetext{
${ }^{49}$ Khankhoje, "Nuevas variedades de maíz", p. 5. Si bien Joseph Cotter ha señalado que Pandurang estaba preocupado sobre todo por estudiar los orígenes genéticos del maíz, lo cierto es que el agrónomo indio desarrolló esta nueva variedad, apta para usos forrajeros, y posteriormente, en 1929, llegó a crear una nueva variedad de trigo que fue probada en el Bajío. Lamentablemente desconocemos los resultados de estos usos. Al respecto, véase CotTer, "Before the Green Revolution”, p. 99.

50 Khankhoje, "Nuevas variedades de maíz", p. 5.

51 Soto Laveaga, "Largo dislocare”, p. 28. Sobre el proyecto posrevolucionario de ingeniería social en México, véase PaLAcios, La pluma y el arado, pp. 61-110.
} 
entorno de artistas, intelectuales y militantes comunistas afincados en la capital durante los primeros años del régimen posrevolucionario. De especial importancia para el legado de la vida y obra de Khankhoje en México resultó la relación establecida con Tina Modotti. La fotógrafa italiana colaboró cercanamente con el agrónomo indio para documentar el trabajo científico y pedagógico desarrollado durante sus primeros años en Chapingo. Sus fotografías, junto con la presencia de Khankhoje en un mural pintado por Diego Rivera en el edificio de la Secretaría de Educación Pública, son el testimonio más elocuente y conocido del paso de Khankhoje por México, y dan muestra de la importante presencia del indio entre los círculos artísticos afines al comunismo de la época. ${ }^{52}$

Los experimentos del recién llegado fueron recibidos con entusiasmo en círculos agraristas y comunistas, dos facciones que durante la década de 1920 buscaban concretar una alianza política y un compromiso ideológico que permitiera a ambas posicionarse de manera estratégica y fortalecida frente al régimen emergente. ${ }^{53}$ En diciembre de 1924, menos de un año de la llegada de Khankhoje a México, su trabajo ocupó un lugar importante en los debates del Segundo Congreso de la Liga de Comunidades Agrarias del Estado de Veracruz. Encabezado por Úrsulo Galván, este Congreso era el resultado de un lustro de movilización y organización de líderes y organizaciones guerrilleras campesinas en Veracruz, cobijadas por el ingeniero y gobernador Adalberto Tejada, en torno del problema de la tierra y la educación campesina. En este Congreso, en el que

52 Las fotografías que resultaron de su colaboración muestran tanto los especímenes híbridos desarrollados por el agrónomo, como a él mismo en los campos experimentales de Chapingo. Están ampliamente disponibles en internet y los originales pueden consultarse en el expediente Escuelas Libres de Agricultura, FIA Savitri Sawnhney, Secretaría de Cultura INAH-SINAFO-FN-MX, resguardado en la Fototeca Nacional en Pachuca.

53 Al respecto, véase JeIfETs y JeIfETs, “La alianza que terminó en ruptura”. 
participaron importantes ideólogos y líderes agraristas de la época como Manuel Almanza, Antonio Echegaray, Carolino Anaya, Isaac Fernández y Agustín Alvarado, se decidió la creación de una organización a nivel nacional; fue un importante hito en la historia del agrarismo posrevolucionario en México. ${ }^{54}$ Durante los años siguientes, y hasta la ruptura que siguió al giro ultraizquierdista de los comunistas y la muerte de Galván en 1929, la Liga tuvo la intención de funcionar como un complemento al PCM en la búsqueda de una política de izquierda que incorporara el reclamo del "ejido como programa mínimo y la socialización de la tierra como programa máximo”. ${ }^{55}$

En este Congreso de diciembre de 1924 de la Liga de Comunidades Agrarias del estado de Veracruz, fuertemente influido por la militancia agrarista radical y comunista, se acordó la creación de las Escuelas Libres de Agricultura (ELA), las cuales tendrían como propósito encabezar la educación de la clase campesina, en especial de los adultos, y proveer los conocimientos prácticos y científicos que pudieran contribuir a la producción agrícola, el cooperativismo y el desarrollo de una pedagogía revolucionaria no capitalista. En virtud de su trabajo en los campos experimentales de Chapingo, se acordó nombrar a Khankhoje director. Durante los primeros dos años de su existencia, el indio encabezó las tareas itinerantes de las escuelas, que funcionaron "por medio de conferencias y demostraciones prácticas” realizadas en los pueblos del Estado de México cercanos a la exhacienda de Chapingo. ${ }^{56}$ En octubre de 1927, Khankhoje presidió la creación de la primer sede de las ELA, nombrada en honor al Caudillo del Sur, Emiliano Zapata, en el pueblo de Chiconcuac, Texcoco. ${ }^{57}$

54 Al respecto véase Fowler Salamini, Agrarian Radicalism in Veracruz, p. 53 y FALcón, El agrarismo en Veracruz, pp. 36, 41-42, donde se señala que el Congreso siguió abiertamente la línea del Partido Comunista Mexicano.

55 ReYnoso, El agrarismo radical, p. 26.

56 Khankhoje, “Escuelas Libres de Agricultura”, p. 188.

57 "Informes de la fundación de la Escuela Libre de Agricultura”, p. 158. 
Para principios del año siguiente había comenzado a coordinar las actividades de otros seis planteles en distintas localidades del Estado de México. ${ }^{58}$ En palabras del propio Khankhoje, en las ELA se buscó establecer una auténtica forma de enseñanza campesina a partir de la superación de la "pedagogía burguesa basada sobre la distinción de las clases y la explotación del hombre para la acumulación del Capital" y el establecimiento de una filosofía edificada sobre la superación del "egoísmo personal" y la "siembra [de] la semilla de la conciencia de clase en los corazones de los alumnos, a base de puro cariño". 59

En 1928, las Escuelas Libres de Agricultura se extendieron por todo el estado de Veracruz, ya convertido en uno de los epicentros del agrarismo radical de la época. Con el apoyo directo del líder revolucionario Úrsulo Galván y del gobernador Adalberto Tejeda, Khankhoje coordinó la creación de cinco nuevas sedes en las que se desarrollaron actividades productivas adaptadas a las diversas regiones naturales del estado: en Fortín, por ejemplo, se creó la Escuela Libre del Café, en Córdoba la Escuela de Agricultura Tropical y en Malibrán la Escuela Libre de Horticultura. ${ }^{60}$ A principios de la década de 1930 , ya después del sonado viraje anticomunista de diciembre de 1928 del presidente Emilio Portes Gil, Khankhoje se mudó a la ciudad de Xalapa, donde se desempeñó como maestro normalista, director de la Escuela Libre de Agricultura "Úrsulo Galván”, miembro destacado del Departamento de Ingeniería Agrícola de la Liga de Comunidades Agrarias del Estado de Veracruz y promotor

58 Sawhney, I Shall Never Ask for Pardon, p. 245.

${ }^{59}$ Khankhoje, "Escuelas Libres de Agricultura”, pp. 188-189. Sobre la construcción del "nuevo campesino" véase PALAcios, La pluma y el arado, pp. 103-109.

${ }^{60}$ Carta del ingeniero Florencio Palomo Valencia, director general de la Secretaría de Agricultura y Fomento, a Pandurang Khankhoje, 10 de junio de 1933, en la que se confirma el entusiasta apoyo del gobierno de Veracruz al plan de abrir cinco sedes de las Escuelas Libres de Agricultura, JNMML, $P S K, S F, 2$, f. 40. 
de sus actividades en distintos rincones del estado. ${ }^{61} \mathrm{Al}$ avanzar la década de 1930, la importancia de su labor científica y política en Veracruz fue reconocida oficialmente y el agrónomo fue nombrado representante del gobierno estatal ante el Consejo Nacional de Agricultura de la Ciudad de México.62

El ascenso de Pandurang Khankhoje en las filas del agrarismo y las ciencias agrícolas del México posrevolucionario alcanzó su punto más alto durante el gobierno de Lázaro Cárdenas. En 1934, el científico indio fue nombrado jefe de la sección de Genética Vegetal en el recientemente creado Instituto Biotécnico, una institución a cargo de la Secretaría de Agricultura y Fomento. ${ }^{63}$ Este Instituto fue creado en 1934 como parte del ambicioso programa de modernización y reforma científica y agrícola del gobierno cardenista. Se constituyó mediante el financiamiento de 100 profesionistas formados en el extranjero y encabezados por el profesor y biólogo Enrique Beltrán, que se conjuntaron para impulsar la investigación en diversas áreas de la ciencia y las actividades productivas, incluyendo la agronomía, la veterinaria y la biología. ${ }^{64}$ Como parte del Instituto Biotécnico, Khankhoje continuó desarrollando experimentos relacionados a la mejora del maíz y en 1936 publicó un estudio pionero en México sobre la soya, un cultivo que por aquellos años se buscaba introducir al campo mexicano para mejorar la dieta de la población rural, así como estudios de sanidad vegetal, sobre las pestes y plagas

${ }^{61}$ José García, presidente de la Liga de Comunidades Agrarias del Estado de Veracruz a Pandurang Khankhojé [sic], 1 de junio de 1932, y Antonio Echegaray, presidente de la Liga Nacional Campesina "Úrsulo Galván”, a Pandurang Khankhoje, 5 de julio de 1932, JNMML, $P S K, S F, 2$, fs. 1 y 5.

${ }^{62}$ Carta del Lic. Gonzalo Vázquez Vela, gobernador de Veracruz, a Pandurang Khankhoje, 10 de mayo de 1934, JNMML, PSK, SF, 4, f. 43.

${ }^{63}$ Oficio 45, Escuela Normal Veracruzana Enrique C. Rebsamen, 29 de enero de 1934, firmado por el profesor Juan Zilli, director, JNMML, PSK, SF 5, f. 30. ${ }^{64}$ GorTari, La ciencia, p. 374. Khankhoje coincidió allí con expertos mexicanos y extranjeros, entre ellos un ruso. Véase Olea-Franco, "One century", pp. $492-500$. 
del naranjo y el plátano. ${ }^{65}$ El Instituto, sin embargo, lograba apenas desenvolverse en medio del "proyectismo" excesivo y pugnas interpersonales, ideológicas e interburocráticas. ${ }^{66}$ Además de su actividad científica durante la primera mitad de la década de 1930, Khankhoje desempeñó diversos cargos oficiales relacionados al programa de modernización agraria del cardenismo: en 1934 fue contratado por el gobierno para participar en la redacción de un plan integral de acción agrícola a nivel nacional ${ }^{67}$ y al año siguiente fue nombrado jefe de la Dirección de Fomento Agrícola encabezada por Tomás Garrido Canabal, quien impulsaba a los radicales "camisas rojas". 68 Para 1939 publicó un estudio sobre el limón mexicano, su importancia, cultivo, mejoramiento y mercado. ${ }^{69}$ Es claro que para finales de la década de 1930, su involucramiento con las actividades pedagógicas, científicas y administrativas del gobierno combinaba el ideal revolucionario de agraristas e izquierdistas con el afán modernizador de los técnicos y burócratas del cardenismo. Tras casi dos décadas de incertidumbre y desplazamientos transcontinentales, Pandurang Khankhoje había encontrado un lugar para desarrollarse profesional y políticamente en el México posrevolucionario.

${ }^{65}$ Khankhoje, "El frijol soya". Sobre sus experimentos con variedades de maíz durante su participación en el Instituto Biotécnico, véase MatcheTT, "Untold Innovation", pp. 55-62.

${ }^{66}$ Sobre el Instituto, véase Olea-Franco, "One Century", pp. 492-500, у СоттеR, “Before the Green Revolution”, pp. 170-175.

67 Oficio 5-404, Secretaría de Agricultura y Fomento, 29 de mayo de 1934, y Oficio 5-840, Secretaría de Agricultura y Fomento, 22 de junio de 1934, JNMML, PSK, SF, 2, ff. 10-14 y 15-16.

${ }^{68}$ Oficio número 03540, Tesorería de la Federación, 1o de enero, 1935, JNMML, PSK, SF, 4, f. 24.

${ }_{69}$ CotTer, Troubled Harvest, p. 163. 
En agosto de 1924, el cónsul británico en la ciudad de México emitió un pasaporte para Pandurang Khankhoje, súbdito indio del Imperio británico y profesor de agricultura en la Escuela Nacional de Agricultura. ${ }^{70}$ Era la primera vez, que sepamos, que el indio itinerante se encontraba en posesión de un documento de identidad oficial. Hasta aquel momento, no tenemos registro de que haya tenido otra forma de acreditar su origen y su estatus como súbdito imperial británico. Según sus memorias, había logrado salir de India en 1905 utilizando una carta expedida por el cónsul estadounidense en Bombay que le permitía viajar a Estados Unidos para estudiar ${ }^{71}$ y en 1914 había viajado a Constantinopla con un pasaporte falso. ${ }^{72}$ Después de la primera guerra mundial, al viajar de Persia a Alemania y, más tarde, a México, Khankhoje se sirvió de documentos otorgados por el Amir del estado de Fars, quien nombraba al indio como su representante en el extranjero. ${ }^{73}$

En 1925, Khankhoje utilizó su nuevo pasaporte británico para iniciar un proceso de naturalización como ciudadano mexicano. ${ }^{74}$ Una vez más, el migrante indio recurrió a sus contactos de la costa oeste de Estados Unidos para apuntalar su presencia en México. Uno de los testigos inicialmente

70 Pasaporte de Pansurang Khankhoje, no. 95/24, AHGE, CN, EPK, s./f. Agradezco a Pablo Yankelevich la orientación en el universo de los archivos de la Secretaría de Relaciones Exteriores y a Daniela Gleizer su generosidad al compartir conmigo importantes materiales utilizados para la redacción de este texto.

71 Sawhney, I Shall Never Ask for Pardon, p. 36.

72 SAwhney, I Shall Never Ask for Pardon, p. 135.

${ }^{73}$ Certificado expedido en el "Cuartel de Su Excelence el Ameer del estado de Ghashghai, Fars-Persa, Amir Atta Khan, Ameer Ashayer (Saulat-s-Saltaneh) Ghashghai Asapas: 3 de noviembre de 1921, JNMML, PSK, SF, 1, ff. 9-11. ${ }^{74}$ José López Cortés, secretario general de Relaciones Exteriores, al C. secretario de Relaciones Exteriores, 24 de julio de 1925, AHGE, EPK, f. 49. 
convocados para declarar en su favor era nada menos que el “Lic. Enrique Flores Magón”, quien había regresado a México a principios de la década después de más de 20 años en Estados Unidos. ${ }^{75}$ Debido a diversos contratiempos administrativos, el trámite se extendió a lo largo de cinco años. A pesar de las demoras, a principios de 1930, el juez del distrito quinto del Distrito Federal recibió una constancia que acreditaba que “el promovente" Pandurang Khankhoje había cumplido con todos los requisitos establecidos por el artículo 13 del Código de Extranjería, “con excepción del relativo a haber observado buena conducta en el País”. ${ }^{76}$ Para remediar esto, Khankhoje presentó un par de cartas en las que se exponían las virtudes de su trabajo científico y su importancia para el futuro del país. La primera, firmada por Waldo Soberón, exaltaba la "laboriosidad e interés” del científico indio por contribuir al desarrollo de la "agricultura nacional” en México. En referencia al trabajo desarrollado desde 1925 en los campos experimentales de Chapingo, Soberón afirmaba que en la Escuela Nacional de Agricultura se había acordado mantener al agrónomo indio como parte de su personal docente y de investigación. ${ }^{77}$ La segunda carta fue redactada por el ingeniero Juan A. González, jefe del Departamento de Extensión de la Dirección General de Agricultura y Ganadería de la Secretaría de Agricultura y Fomento. El mensaje del ingeniero estaba lleno de entusiasmo y enfatizaba el gran logro que representaba para "la agricultura nacional" la "creación de variedades de cereales hasta hoy desconocidas en el País” a manos de Khankhoje. González resaltaba que, además de haber publicado los hallazgos en revistas científicas,

75 Oficio firmado por P. K. y dirigido al C. Juez Tercrero de Distrito Supernumerario, julio 21 de 1926, AHGE, CN, EPK, ff. 6-8.

${ }^{76}$ Licenciado Horacio Terán al C. Juez Quinto de Distrito del Distrito Federal, 14 de febrero de 1930, AHGE, CN, EPK, f. 31.

77 Ingeniero Waldo Soberón al C. Secretario de Relaciones Exteriores, 3 de marzo de 1930, AHGE, CN, EPK, f. 37. 
el agrónomo indio estaba comprometido con impartirlos "personalmente en las Escuelas Libres de Agricultura que ha[bía] fundado en el Estado de México, y a las que concurren alumnos campesinos en su totalidad". ${ }^{78}$ Poco después de la recepción de estas cartas, en junio de 1930, el nativo de Maharashtra recibió su constancia de naturalización. ${ }^{79}$

Su proceso de nacionalización presenta una interesante anomalía que ilustra el funcionamiento contradictorio, y flexible, de los trámites de naturalización de extranjeros "inasimilables" o indeseados en México durante las décadas de 1920 y 1930.80 A pesar de la reducida presencia de inmigrantes en México -a principios del siglo no representaban ni el 1\% de la población nacional-, ${ }^{81}$ como parte de la cristalización de la política migratoria del régimen posrevolucionario se promovió la idea de que los individuos de ciertas "razas" y nacionalidades eran inasimilables a la nación mexicana. Como es sabido, este rechazo tomó tintes dramáticos y violentos en lo que respecta a las comunidades de origen chino en México, especialmente en estados norteños como Sonora y Coahuila. ${ }^{82}$ Queda claro que, en este entorno de creciente xenofobia, la solicitud de naturalización de Khankhoje se vio beneficiada por la participación de figuras como Waldo Soberón y Enrique Flores Magón. Sin embargo, me parece que su nacionalización no puede ser entendida solo como el resultado de "las palancas" de sus allegados. El éxito de su solicitud obedece sobre todo al hecho de que, a diferencia

\footnotetext{
78 Ingeniero Juan A. González al C. Secretario de Relaciones Exteriores, 5 marzo de 1930, AHGE, CN, EPK, f. 36.

79 Expediente de naturalización ordinaria, 1930, AHGE, CN, EPK, f. 1-2.

80 Autores como Pablo Yankelevich y Daniela Gleizer han dejado en claro la lógica altamente arbitraria y desgastante detrás de los procesos de naturalización en aquellos años. Al respecto, véase Gleizer, "Los límites de la nación", y YANKeLEVICH, "Mexicanos por naturalización".

${ }^{81}$ Yankelevich, "Mexicanos por naturalización”, p. 1739.

82 Para más sobre el antichinismo en México véase Chang, Chino, y Ramírez Zavala, "La justificación higiénico-sanitaria".
} 
de otros "asiáticos" a quienes se asociaba con el desarrollo de actividades "parasitarias" o peligrosas, Khankhoje desde un primer momento se insertó como participante en el proyecto científico, pedagógico y político del agrarismo gubernamental. La insistencia de Soberón y González respecto a su relevancia para el futuro de la "agricultura nacional" dejaba en claro que Khankhoje no solo cumplía con los requisitos legales para naturalizarse mexicano, sino que su labor era reconocida como una importante contribución al proyecto de justicia social y modernización del Estado mexicano posrevolucionario.

Al mismo tiempo, quizá no sea demasiado arriesgado sugerir que la ambigua posición de los indios -o "indostanos" como eran descritos en la época- dentro de las clasificaciones raciales de la época fuera un factor importante en la fácil adaptación de Khankhoje en el orden establecido por el proyecto de mestizaje impulsado por el gobierno posrevolucionario. Más arriba vimos que durante sus años en Estados Unidos, Khankhoje se percató de las similitudes fenotípicas entre indios y mexicanos, dos comunidades excluidas de las amorfas categorías raciales utilizadas en la época, como "orientales/asiáticos", "negros" o "blancos". Esta similitud generó un importante espacio de intercambio y contacto que fue más allá de lo ideológico, como queda patente con el surgimiento de una comunidad de punjabi-mexicanos en la costa oeste estadounidense a lo largo de la década de 1910. A pesar de las leyes antimestizaje vigentes en California durante esos años, que prohibían el matrimonio entre individuos de distintas razas, a partir de 1916 se celebraron numerosos matrimonios entre hombres provenientes del Punjab y mujeres mexicanas, dando paso a una nueva colectividad unida por la común de las convenciones racistas de la época. ${ }^{83}$ Hacia el final de su vida, Khankhoje haría referencia a estas coincidencias al bromear con que, tras tres décadas de trabajo entre los campesinos

$83 \mathrm{Al}$ respecto, véase Isaksen Leonard, Making Ethnic Choices. 
de México, había acabado por ser “doblemente indio", 84 en referencia a la tierra de su nacimiento y al pilar indígena del nacionalismo mexicano.

Independientemente de estas consideraciones raciales, está claro que la importancia científica de Khankhoje y su trayectoria como agrónomo apuntaló su proceso de naturalización en México. Más allá de su trabajo científico y docente, durante los años siguientes a su naturalización Khankhoje tuvo la oportunidad de crear una familia en México. En 1936 se casó con Jeanne Sindic, una mujer de origen belga que había sido adoptada por Luis Ricoy, un antiguo funcionario de la embajada mexicana en Bruselas, con la que tuvo dos hijas. ${ }^{85}$ Doce años después de su llegada a México, el antiguo activista antibritánico disfrutaba de un éxito profesional y una estabilidad personal que no había conocido en su vida previa como activista anticolonial y estudiante en distintas partes del mundo.

DEL AGRARISMO A LA AGROINDUSTRIA (1936-1954)

Durante la segunda mitad de la década de 1930, Khankhoje pasó de estar empleado en la estructura del Estado posrevolucionario a convertirse en un trabajador del sector privado. Como muchos otros agrónomos de la época, Khankhoje se vio afectado por la creciente crisis del campo mexicano causada por la conjunción de sucesivas oleadas de plagas, el descenso en la productividad y la incapacidad de los productores agrícolas para vender sus productos en el mercado durante los últimos años del cardenismo. ${ }^{86}$ En 1936, Pandurang Khankhoje dejó su trabajo en el Instituto Biotécnico al ser nombrado "gerente del Departamento Industrial y Agrícola” del Ferrocarril Sud Pacífico de México. Tras

84 SAwHney, I Shall Never Ask for Pardon, p. 266.

85 SAWHney, I Shall Never Ask for Pardon, pp. 254-270.

86 CotTer, Troubled Harvest, pp. 126-157. 
mudarse con su familia a Tepic, el agrónomo fue puesto a cargo de actividades de reconocimiento y experimentación impulsadas por la compañía en la “zona de defensa del noroeste”, un vasto territorio que abarcaba Nayarit, Sinaloa, Sonora y Baja California. Armado con un permiso de la Secretaría de Agricultura y Fomento y fondos de la compañía, Khankhoje montó un "laboratorio ambulante para estudios científicos” en un vagón de tren, a bordo del cual recorrió territorios clave para el posterior desarrollo de la agroindustria -como los valles del río Yaqui, Guasave, Culiacán y Navolato- realizando distintos experimentos agrícolas. ${ }^{87} \mathrm{~A}$ partir de este momento, su trayectoria profesional y vivencial dio un marcado giro. Su involucramiento con las políticas agrarias y agrícolas del Estado mexicano comenzó a estar vinculado a su participación científica en el sector industrial y, cada vez más, el capital privado. Como veremos, este fue un proceso que se extendió a lo largo de dos décadas y que reflejaba un cambio más amplio en la relación entre gobierno y capital privado en México. En lo personal, Khankhoje comenzó a ganar un mejor salario -durante años no había cobrado un solo peso por su papel como director de las Escuelas Libres de Agricultura y había sobrevivido con su salario como profesor de Chapingo e investigador del Instituto Biotécnico-, lo que le permitió mantener a su nueva esposa y a sus hijas y, en los años que siguieron, vivir una vida holgada y cómoda.

La historia del Ferrocarril Sud Pacífico de México está íntimamente ligada a la transformación económica y política del Noroeste de México y al nacimiento de la agroindustria en estados como Sonora y Sinaloa. El Ferrocarril Sud Pacífico de México comenzó a operar en 1905, cuando la compañía adquirió los derechos para construir vías de ferrocarril que conectarían las tierras del valle del río Yaqui, recientemente adquiridas por la

87 Oficio 11-5-40151 de la Secretaría de Agricultura y Fomento, firmado por el director J. de J. Urquizo, 16 de noviembre 1936, JNMML, $P S K, S F$, 4, f. 34-35. 
Compañía Constructora Richardson, con Estados Unidos y el centro del país. ${ }^{88}$ Durante los últimos años de su gobierno, la construcción de la vía Empalme-Tepic, que uniría Nogales con el centro del país, fue una prioridad para Porfirio Díaz, sobre todo a partir de que en 1906 la huelga de Cananea dejara clara la volatilidad del ambiente político sonorense. Sin embargo, debido a las dificultades del terreno, la inestabilidad política y la resistencia de las poblaciones yaquis del sur de Sonora, la construcción de la vía no se terminó sino hasta 1911. El estallido revolucionario hizo que la construcción del último tramo TepicLa Quemada, que unió la vía con Guadalajara, se retrasara hasta 1927. ${ }^{89}$ A pesar de estos retrasos inconvenientes, desde muy temprano el enorme potencial económico que inauguraba la nueva línea fue vaticinado por funcionarios gubernamentales, como el propio Obregón, quien tenía vastas propiedades cerca de Navojoa, y numerosos empresarios. En 1910, un oficial del gobierno de Díaz celebraba que "el gran impulso" generado por el ferrocarril a la producción agrícola de las ricas planicies de Sinaloa y la costa de Sonora "abría espacio para la exportación de innumerables cantidades de garbanzos, jitomates, naranjas, melones, sandías, pimientos y otros productos $[. .$.$] que nunca$ antes habían sido considerados para la extracción". $9^{0}$ Ya desde los últimos años del porfiriato, el ferrocarril hacía posible vislumbrar la explotación del nuevo y enorme potencial económico que ofrecía la agricultura masificada. ${ }^{91}$

\footnotetext{
${ }^{88}$ DwYer, The Agrarian Dispute, pp. 23-25.

${ }^{89}$ LEwIs, Iron Horse Imperialism, pp. 43-66.

90 G. González a la Secretaría de Comunicaciones y Obras Públicas, 14 de julio, 1910. Reporte titulado "Ferrocarril de Sonora, Compañía del Ferrocarril Sud Pacífico de México", Archivo General de la Nación, Colección de la Secretaría de Comunicaciones y Obras Públicas, citado en Lewis, Iron Horse Imperialism, p. 49.

91 Para más información, véase Gracida Romo, La historia del Ferrocarril Sud Pacífico de México, y Carrillo Rojas y Rivas Sada (coords.), Agricultura empresarial en el Norte de México.
} 
A partir de su vinculación profesional con el Ferrocarril Sud Pacífico, y durante la siguiente década, Khankhoje se volvió un activo promotor de los vínculos entre los intereses del capital privado y el gobierno en México en cuestiones de producción agrícola a gran escala. En 1936, fue nombrado "comisionado de la Secretaría de Agricultura y Fomento" en Nayarit, y se le aseguraron todas las facilidades para "llevar a la práctica todo género de experimentaciones agrícolas que [estimara] convenientes" en las estaciones agrícolas del Ferrocarril Sud Pacífico de México en el estado. ${ }^{92}$ Estas estaciones, que replicaban el modelo instaurado en Chapingo en 1924, fueron establecidas durante estos años en distintos puntos de la costa del Pacífico y funcionaban como sedes experimentales conjuntas del gobierno y de la compañía. En 1938, el científico recibió el nombramiento oficial de "Agrónomo Regional Honorario" de la "región territorial que atraviesa el Ferrocarril Sud Pacífico", ${ }^{93}$ y en años posteriores el naturalizado ejerció simultáneamente como alto empleado de la compañía estadounidense y como "inspector y asesor técnico" de la Secretaría de Agricultura y Fomento en los estados de Sonora, Sinaloa, Nayarit, Colima y Jalisco. ${ }^{94}$ Para principios de la década de 1940, el desplazamiento geográfico de Khankhoje desde Veracruz hacia el Noroeste se veía reflejado en su tránsito del agrarismo a la agroindustria.

En la década de 1940, las habilidades de Khankhoje llamaron la atención de importantes hombres de negocios. Esto hizo que sus actividades en el sector privado se extendieran más allá de su inicial involucramiento con los Ferrocarriles Sud Pacífico de

92 Oficio IV-1836, Secretaría General de Gobierno, Estado de Nayarit, 19 de noviembre de 1936, JNMML, PSK, SF, 4, f. 44.

93 Carta de Ing. Fernando Foglio, Subsecretario de la Agricultura y Fomento del Poder Ejecutivo Federal, a Khankhoje, 26 de marzo de 1938, JNMML, PSK, SF, 4, f. 45.

94 Oficio 204.2.8055 de la Secretaría de Agricultura y Fomento, 10 de abril de 1940, JNMML, PSK, SF, 4, f. 47. 
México. En 1941, Walter Douglas, ingeniero minero de origen canadiense, colaborador científico de los Ferrocarriles Sud Pacífico de México y presidente de la Charles Wilson Co., señaló que el agrónomo de origen indio poseía una "habilidad única" para desarrollar trabajo en las "secciones tropicales" del territorio mexicano. El canadiense afirmaba además que, habiéndose desempeñado como director de las estaciones experimentales de la compañía durante años y obtenido la nacionalidad mexicana, Pandurang Khankhoje era "el hombre ideal" para encargarse de la expansión de nuevos cultivos comerciales altamente redituables en México. Entre éstos, resaltaba el caucho, un producto que por aquellos años se convirtió en un importante insumo para el esfuerzo bélico de las potencias europeas y del Atlántico Norte. ${ }^{95}$ A los pocos meses, en octubre de 1941, el científico fue enviado a Chiapas en calidad de representante de "inversionistas residentes en la Capital de la República" interesados "en la explotación de hule", ${ }^{96}$ y para enero de 1942, el científico se hallaba trabajando como promotor de la expansión del cultivo del caucho en el estado de Tabasco y los campos de la United Fruit Company en el sur de Veracruz. ${ }^{97}$ El involucramiento de Khankhoje con la producción de caucho debe ser vista a la luz de la campaña orquestada desde Estados Unidos para resolver el constreñimiento al aprovisionamiento del hule proveniente del sureste asiático como resultado de la expansión japonesa en las costas del Pacífico durante los primeros años de la segunda guerra mundial. En aquel mismo periodo,

${ }^{95}$ Carta de Charles Wilson a Walter Douglas, 1 de junio de 1941, JNMML, PSK, SF, 4, f. 12.

${ }^{6}$ Oficio 254-5-p de la secretaria particular de Rafael P. Gamboa, gobernador de Chiapas, para los presidentes municipales del Estado, 10 de octubre, 1941, JNMML, $P S K, S F, 4$, f. 49.

97 Oficio IV.5. (726.2) /131 de la Secretaría de Educación Pública de Tabasco para los maestros rurales federales y estatales del Estado, 10 de enero de 1942, JNMML, $P S K, S F, 4$, f. 50. 
entre 1941 y 1943, el gobierno estadounidense, desesperado por hallar proveedores de caucho en el continente americano, gestionaba -con el gobierno de Getulio Vargas en Brasil- una campaña de intercambio a gran escala de este cultivo. ${ }^{98}$ Debido a la delicada situación internacional y a la creciente importancia de la colaboración entre agencias de los gobiernos de México y Estados Unidos durante los primeros años de la década de 1940, las actividades de Khankhoje durante aquellos años recibieron apoyo militar directo coordinado por el jefe del Estado Mayor Presidencial. ${ }^{99}$

A lo largo de la década de 1940, Khankhoje siguió actuando en cercana colaboración con altas esferas del gobierno mexicano. En sus trabajos de exploración y prospección en el sur del país, recibió el apoyo del gobernador de Chiapas, Rafael Pascacio Gamboa, quien instruyó a comisarios ejidales y organizaciones campesinas chiapanecas que le brindasen al visitante todas las facilidades para su labor como científico. Por medio de Gamboa, quien en 1945 actuaría como director de campaña del candidato oficialista y en 1946 sería nombrado el primer presidente del flamante Partido Revolucionario Institucional, Khankhoje entró en contacto con círculos políticos cercanos al futuro presidente Miguel Alemán. Al finalizar la guerra, el nativo de Maharashtra se codeaba con las altas esferas del poder en México: en 1947, el secretario particular de Miguel Alemán, Jorge Viesca, impulsó un proyecto ideado por Khankhoje para crear nuevos campos de "experimentación agrícola para desarrollar en la cuenta [sic] del Papaloapan", una de las regiones clave del plan de desarrollo alemanista. ${ }^{100} \mathrm{~A}$ pesar de que esta última iniciativa nunca se

\footnotetext{
98 Véase Wilkinson, “Tapping the Amazon from Victory”.

99 Carta del Gral. J. Salvador S. Sánchez, Jefe del Estado Mayor, a Tte. Nicolás Andrade Corro, Comandante del Destacamento Militar, Santa Lucrecia, Ver., 23 de noviembre de 1942, JNMML, PSK, SF, 4, f. 53.

100 Ricardo José Zavala a Lic. Don Jorge Viesca, Secretario Particular del Sr. Presidente de la República", 17 de junio de 1947, JNMML, PSK, SF, 4, f. 25.
} 
concretó, queda claro que, tras haber participado activamente en los círculos agraristas de las décadas de 1920 y 1930, para la segunda mitad de la década de 1940 Khankhoje se movía cómodamente entre los impulsores y defensores del nuevo modelo de desarrollo nacional poscardenista que en años posteriores sería identificado con la fórmula del "desarrollo estabilizador".

Tras dos décadas en México, Khankhoje había encontrado el éxito profesional y la estabilidad económica. Durante los años siguientes, Khankhoje continuó siendo un empleado de la iniciativa privada -incluida la compañía Vicks Chemicals, para la cual comenzó a trabajar en 1946-101 lo que le permitió proveer a su familia con una vida cómoda y privilegiada. Sin embargo, tras la independencia de la India en 1947, el agrónomo comenzó a buscar la manera de volver a la tierra donde nació. Para esto recurrió a sus contactos en el gobierno de Miguel Alemán, por medio de los cuales fue comisionado en 1951 como responsable de establecer relaciones culturales y diplomáticas con la nueva República de la India. ${ }^{102}$ Con esta encomienda, Pandurang pasó dos años en la India, donde fue recibido como un ciudadano mexicano. Tras volver a México en 1953, se desprendió de todo su patrimonio y sus compromisos profesionales con miras a abandonar el país definitivamente. En noviembre de 1954 realizó el viaje de regreso a su tierra natal; su esposa y sus hijas lo alcanzaron en 1956. El científico pasó sus últimos años en Maharashtra, su región de nacimiento. A pesar de su brillante trayectoria profesional en México, se vio incapaz de obtener un trabajo como científico o profesor en la India independiente.

101 Sawhney, I Shall Never Ask for Pardon, p. 267.

102 Esta comisión es mencionada por Pandurang Khankhoje en una carta enviada a Bhagwan Singh Gyanee el 7 de octubre de 1953, SAADA, BSGM, https://www.saada.org/item/20120723-824, consultada el 10 de mayo de 2018. Ana Savitri Sawhney, la hija de Khankhoje, en una entrevista me reveló que esta comisión había sido obtenida por medio de los contactos de Khankhoje con Salomón de la Selva, secretario personal de Miguel Alemán. 
En la década de 1960 comenzó a recibir una pensión del Estado indio que le permitió vivir modestamente y le fue otorgada la nacionalidad india. Al poco tiempo de su llegada, su esposa Jeanne, más de diez años menor que Pandurang, se mudó a Delhi, donde había conseguido un trabajo, y sus hijas pronto formaron sus propias familias. El científico itinerante murió acompañado por un pariente lejano en la ciudad de Nagpur en $1965 .{ }^{103}$

\section{EPÍLOGO: PANDURANG KHANKHOJE Y LA PREHISTORIA DE LA REVOLUCIÓN VERDE}

La brillante carrera científica de Khankhoje en México inició con su trabajo en los campos experimentales de la Escuela $\mathrm{Na}$ cional de Agricultura en 1924, bajo la dirección del ideólogo agrarista y convencido modernizador Marte R. Gómez. Diecisiete años después, en 1941, mientras Khankhoje exploraba las regiones tropicales de México en busca de terrenos propicios para la siembra del caucho, en un entorno internacional marcado por las tensiones generadas por el estallido de la segunda guerra mundial, el ingeniero Gómez -cuya larga carrera política iniciada en su juventud agrarista había florecido con su paso por Chapingo como director y quien entonces se desempeñaba como secretario de Agricultura y Fomento en el gobierno de Manuel Ávila Camacho- se aproximó a la Fundación Rockefeller para solicitar asistencia técnica. Buscaba ayuda para completar la revolución agrícola iniciada en México durante la década de 1920. Como respuesta al llamado de Gómez, en julio de 1941 tres científicos agrícolas estadounidenses $-\mathrm{E}$. C. Stakman, Richard Bradfield y Paul C. Mangelsdorf-104 llegaron a México y

\footnotetext{
103 Sawhney, I Shall Never Ask for Pardon, pp. 298-304.

104 Mangelsdorf, quien había realizado experimentos en torno de la mejora del maíz en los campos experimentales de la Universidad de Texas, conocía el trabajo de Khankhoje y lo había citado como parte de sus publicaciones científicas. Véase Mangelsdorf y Reeves, The Origin of Indian Corn, p. 9.
} 
fueron recibidos como huéspedes en la exhacienda de Chapingo. Durante los siguientes meses, los tres extranjeros realizaron un largo viaje de prospección por distintas regiones de México y recopilaron un extenso informe de sus impresiones del estado de la agricultura en el país. A partir de este informe, redactaron un plan de acción para la modernización de la agricultura en México enfocado a incrementar la productividad del campo con miras a cumplir con las crecientes necesidades alimentarias de su población..$^{05}$

Con base en el plan delineado por Stakman, Bradfield y Mangelsdorf, en 1943 se inauguró la Oficina de Estudios Especiales en Texcoco, a escasa distancia de la Escuela Nacional de Agricultura. Esta Oficina, que contaba con apoyo de la Secretaría de Agricultura y Fomento y fondos de la Fundación Rockefeller, fue inicialmente encabezada por George Harrar y recibiría al poco tiempo de su creación al luego ganador del Premio Nobel, Norman Borlaug. Ambos eran egresados de la Universidad de Minnesota. Los trabajos experimentales de la Oficina, que a la postre se convertiría en la sede del Centro Internacional de Mejoramiento del Maíz y el Trigo - un conglomerado de científicos y centros de estudios con presencia alrededor del mundo en países como Kenia, Turquía, Kazakistán, Colombia, Etiopía, Pakistán y China-, comenzaron a desarrollarse en los campos experimentales cercanos a Chapingo, en los que, entre 1924 y 1925, el agrónomo indio Pandurang Khankhoje había desarrollado sus variedades de maíz. En los años siguientes, no sería el maíz, sino el trigo, el cereal que concentró la atención de científicos y autoridades agrícolas en México. Para mediados de la década de 1950, nuevas semillas desarrolladas a partir del trabajo científico de la Oficina de Estudios Especiales contribuyeron al crecimiento exponencial de la producción de trigo, especialmente en las fértiles tierras del sur de Sonora, por las cuales corrían

105 Stakman et. al., Campaigns against Hunger, pp. 3-35. 
las vías del Ferrocarril Sud Pacífico de México. Para finales de aquella década, el exitoso experimento en Sonora hizo que México llegara a ser autosuficiente en su producción de trigo y comenzara a ser visto en el extranjero como un modelo para el resto del Tercer Mundo. ${ }^{106}$ En mayo de 1966, un cargamento de 18000 t de semillas de la variedad de trigo Lerma Rojo, desarrollada en Ciudad Obregón, zarparon desde el puerto de Guaymas con dirección a India, donde se utilizarían para paliar los devastadores efectos de la sequía de Bihar de 1966-1967. $\mathrm{Al}$ año siguiente de su muerte, los frutos lejanos del visionario trabajo científico de Khankhoje en México retornaban a India en la forma de semillas de trigo híbridas.

Con este envío, que representó la mayor compra internacional de semillas realizada en el mundo hasta aquel momento, se consolidaba un triángulo de intercambio y comunicación entre México, Estados Unidos e India que había comenzado a fraguarse en septiembre de 1965, cuando el gobierno de Lal Bahadur Shastri entabló negociaciones con la Fundación Rockefeller para el envío de semillas de trigo desde México para paliar la escasez de grano causada por la sequía y la guerra con Pakistán. Tras la muerte de Shastri, en enero de 1966, la nueva primer ministro, Indira Gandhi, cerró el trato durante una visita a Washington en marzo de aquel año. Apenas unas semanas después, un grupo de tres científicos comisionados por el Instituto Indio de Investigaciones Agrícolas viajó a Sonora para realizar la selección y organizar el envío de las semillas. Este momento marca el inicio de la exportación del modelo de modernización agrícola más tarde conocido como la revolución verde de México a India y el inicio del cultivo a gran escala de variedades de trigo de alto rendimiento en Asia. ${ }^{107}$

106 Véase HewitT de Alcántara, Modernizing Mexican Agriculture, y BorLAUGH, La Revolución Verde.

107 Perkins, Geopolitics and the Green Revolution, pp. 240-245. 
La vida del agrónomo y revolucionario itinerante Pandurang Khankhoje, y su paso por México, nos ofrece una fascinante ventana para el estudio global de importantes procesos de transformación política, ideológica y científica del pasado siglo xx. En este artículo me he enfocado en resaltar que los años en los que Khankhoje transitó del agrarismo a la incipiente agroindustria en México coinciden con el ciclo agrarista radical y la expansión del PC en México, y con el despunte de los procesos que más tarde serían identificados con el inicio de la revolución verde. A pesar de que tenemos suficientes indicios como para reconstruir su trayectoria en México, aún no se ha localizado evidencia documental completa de los resultados obtenidos en los trabajos de experimentación fitogenética y de biología vegetal de Pandurang en el campo, ni de los resultados de su práctica como docente rural. Asimismo, a causa de la escasez de testimonios dejados por el propio Khankhoje, es difícil identificar con claridad su postura respecto a los diferentes paradigmas y escuelas científicos de la época, así como también profundizar más en los procesos científicos y políticos en los que estuvo involucrado durante su paso por México. Sin embargo, su compromiso con la labor científica y pedagógica de la Escuela Nacional de Agricultura y las Escuelas Libres de Agricultura, así como del naciente entramado institucional dedicado a la innovación científica del cardenismo, son coherentes con sus antecedentes antiimperialistas. Más aún, al observar su trayectoria en México, así como sus vínculos y convergencias con la historia científica, política y económica del país, queda claro que el sueño de los agraristas del México posrevolucionario, como el propio Pandurang, tuvo puntos de encuentro con el de los científicos estadounidenses financiados por la Rockefeller a partir de la década de 1940 y los nacionalistas anticoloniales indios de finales del siglo xIX. El más claro de estos puntos de encuentro era la búsqueda común por erradicar el hambre. En una época previa al extendido debate en torno de los organismos genéticamente modificados y 
el impacto ambiental de las técnicas de cultivo agroindustrial, las trayectorias revolucionarias del agrarismo y la agroindustria avanzaron en paralelo para alimentar, desde México, el inicio de la dramática transformación de la producción de alimentos a nivel global durante las primeras décadas de la posguerra. En este sentido, la historia del agrónomo itinerante Pandurang Khankhoje ejemplifica a la perfección el argumento trazado por Joseph Cotter, según el cual en el México de la primera mitad del siglo xx los agrónomos -que transitaron de ser agentes activos de la Revolución a convertirse en profesionales científicos-son centrales para comprender las dinámicas nacionales de la revolución mexicana en su interconexión con las transformaciones globales de la revolución verde. ${ }^{108}$ Como he argumentado en este texto, el paso por México de Khankhoje nos permite identificar y rastrear muchos de los hilos sueltos de esta trama para entender que, lejos de ser una mera historia de neocolonialismo económico, el origen de la revolución verde es el resultado de la conjunción de diversos proyectos modernistas, incluso utópicos, que unían a campesinos, científicos, ideólogos y activistas de diversos orígenes actuando alrededor del mundo en las décadas intermedias del pasado siglo Xx.

108 COTTER, Troubled Harvest. 


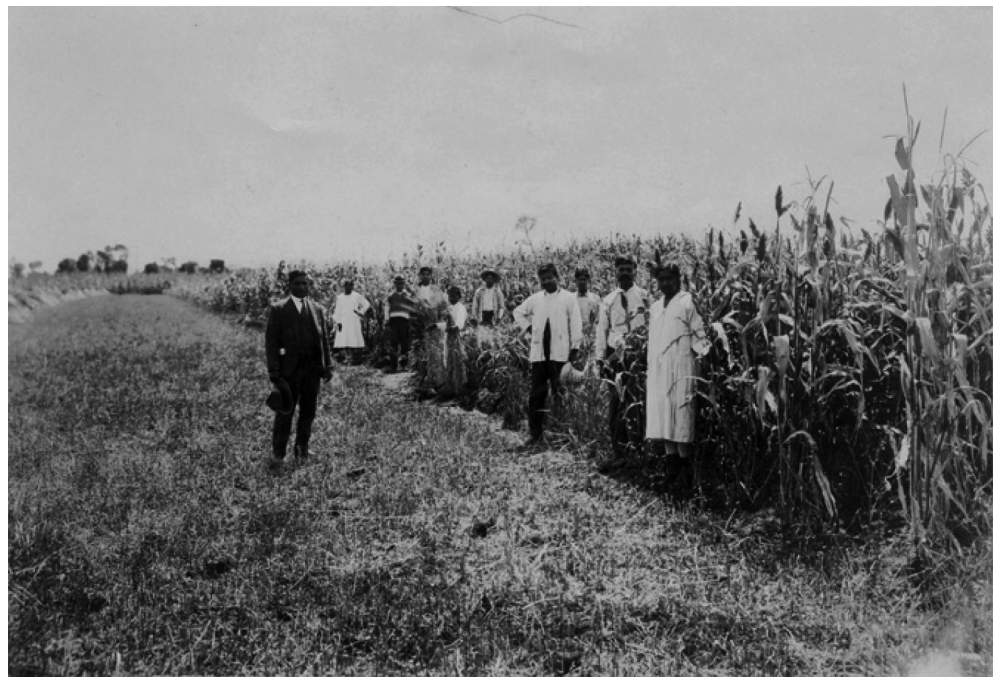

Pandurang Khankhoje (de traje, a la izquierda) con alumnos en los campos experimentales de la Escuela Libre de Agricultura Emiliano Zapata, Chiconcuac, Texcoco, Estado de México, 1930. Fototeca Nacional, Instituto Nacional de Antropología e Historia, https://mediateca.inah.gob.mx/repositorio/islandora/object/fotografia/3A468937 (fecha de actualización, 12 de julio de 2019). 


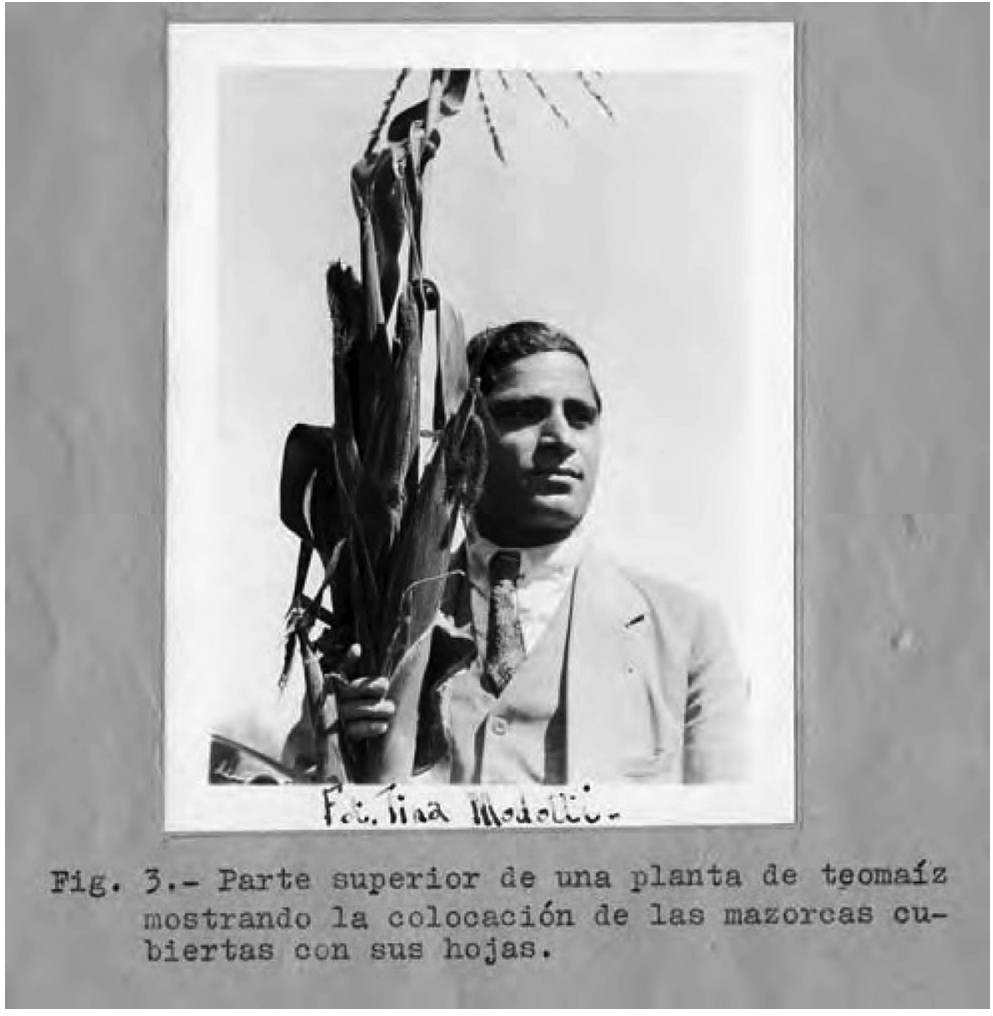

Tina Modotti, Pandurang Khankhoje presentando una nueva variedad de maíz, c. 1928, tomada de https://www.documenta14.de/en/south/903_revolutionary_work_pandurang_khankhoje_and_tina_modotti (fecha de actualización, 12 de julio de 2019). 


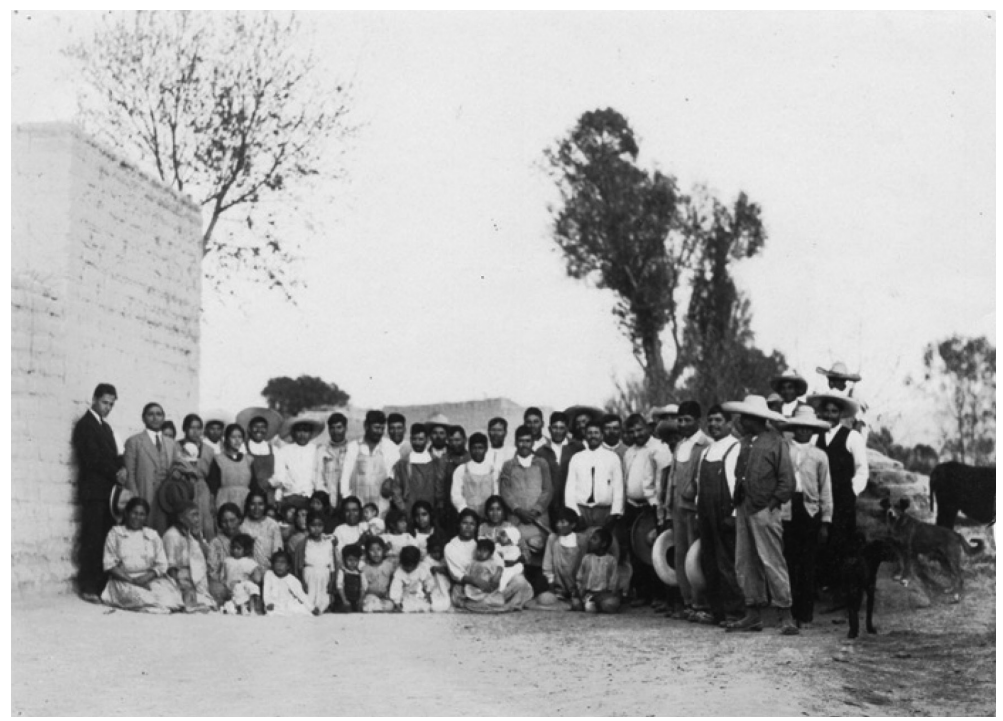

Tina Modotti. Pandurang Khankhoje, segundo desde la izquierda, de pie, en la inauguración de la Escuela Libre de Agricultura de Tocuila, Estado de México, 1928, Fototeca Nacional, Instituto Nacional de Antropología e Historia, https://mediateca.inah.gob.mx/repositorio/islandora/object/ fotografia/3A468946 (fecha de actualización 12 de julio de 2019). 


\section{SIGLAS Y REFERENCIAS}

AHGE, CN, EPK Archivo Histórico Genaro Estrada, fondo Cartas de Naturalización, exp. de Pandurang Khan-Khoje, Clasificación Decimal III/521.2 (42)/134, Topográfica VII (N)-242-6, México D. F.

JNMML, PSK, SF Jawaharlal Nehru Memorial Museum and Library, P. S. Khankhoje Papers, Subject Files, Delhi, India.

SAADA, BSGM South Asian American Digital Archives, Bhagwan Singh Gyanee Materials.

BaILey, C. H., "The composition and quality of Mexican wheats and wheat flours", en Journal of the American Society of Agriculture, 6: 2 (mar.-abr. 1914), pp. 57-64.

Barahona Echeverría, Ana, Susana Pinar y Francisco José Ayala, La genética en México: institucionalización de una disciplina, México, Universidad Nacional Autónoma de México, 2003.

Boyer, Chris y Micheline Cariño, "Mexico’s Environmental Revolutions”, en Leal, Padua y Soluri (coords.), 2013, pp. 9-15.

Carrillo Rojas, Arturo y Eva Rivas SAda (coords.), Agricultura empresarial en el Norte de México (siglo XX). Actores y trayectoria de la economía regional, México, Plaza y Valdés Editores, 2016.

Cerutti, Mario, "La agriculturización del desierto. Estado, riego y agricultura en el norte de México (1925-1970)", en Apuntes, $42: 77$ (jul.-dic. 2015), pp. 91-127.

Chang, Jason Oliver, Chino. Anti-Chinese Racism in Mexico, 1880-1940, Chicago, University of Illinois Press, 2017.

Chitra (drama en un acto), traducción de Heramba Lal Gupta, México, La Helvetia, 1919.

Cotter, Joseph, Troubled Harvest. Agronomy and Revolution in Mexico, 1880-2002, Westport, Connecticut, Praeger Publishers, 2002.

CotTER, Joseph, "Before the Green Revolution: Mexican Agricultural Science Policy, 1920-1949", tesis de doctorado, California, University of California at Santa Barbara, 1993. 
DwYER, John, The Agrarian Dispute. The Expropriation of American-Owned Rural Land in Postrevolutionary Mexico, Durham, N. C., Duke University Press, 2008.

FALCón, Romana, El agrarismo en Veracruz. La etapa radical (1928-1935), México, El Colegio de México, 1977.

Fowler Salamini, Heather, Agrarian Radicalism in Veracruz, 1920-1938, Lincoln, Nebraska, University of Nebraska Press, 1971.

Fraser, T. G., “Germany and Indian Revolution, 1914-1918”, en Journal of Contemporary History, 12 (1977), pp. 255-272.

Gleizer, Daniela, "Los límites de la nación. Naturalización y exclusión en el México posrevolucionario”, en Gleizer y López Caballero (coords.), 2015.

Gleizer, Daniela y Paula López Caballero (coords.), Nación y alteridad. Mestizos, indígenas y extranjeros en el proceso de formación nacional, México, Universidad Autónoma Metropolitana-Cuajimalpa, 2015.

Goebel, Michael, "Una biografía entre espacios: M. N. Roy. Del nacionalismo indio al comunismo mexicano", Historia Mexicana, LXII: 4 (248) (abr.-jun. 2013), pp. 1459-1495.

Gómez, Marte R., La Reforma Agraria de México. Su crisis durante el periodo 1928-1934, México, Porrúa, 1964.

Gómez, Marte R., Historia de la Comisión Nacional Agraria, México, Centro de Investigaciones Agrarias, Secretaría de Agricultura y Ganadería, 1975.

Gortari, Eli de, La ciencia en la historia de México, México, Grijalbo, 1964.

Goswami, Manu, Producing India: From Colonial Economy to National Space, Chicago, University of Chicago Press, 2004.

Gracida Romo, Juan José, La historia del Ferrocarril Sud Pacífico de México y del Río Mayo: durante el Porfiriato y la Revolución Mexicana 1905-1932, Hermosillo, Sonora, México, Universidad de Sonora, 2014.

GuHA, Ranajit, Dominance Without Hegemony. History and Power in Colonial India, Cambridge, Mass., Harvard University Press, 1997. 
GutiérReZ NúÑEZ, Netzahualcóyotl Luis, “Cambio agrario y revolución verde: dilemas científicos, políticos y agrarios en la agricultura mexicana del maíz, 1920-1970", tesis de doctorado en historia, México, El Colegio de México, 2017.

Heatherton, Christina, "The Color Line and the Class Struggle: The Mexican Revolution and Convergences of Radical Internationalism, 1910-1946", tesis de doctorado en historia, California, University of Southern California, 2012.

Hewitt de Alcántara, Cynthia, Modernizing Mexican Agriculture: Socioeconomic Implications of Technological Change, 1940-1970, Ginebra, United Nations Research Institute for Social Development, 1976.

Illades, Carlos (coord.), Camaradas. Una nueva historia del comunismo en México, México, Secretaría de Cultura y Fondo de Cultura Económica, 2017.

"Informes de la fundación de la Escuela Libre de Agricultura 'Emiliano Zapata' organizada por la Liga de Comunidades Agrarias del Estado de México y establecida en San Miguel Chiconcuac, Texcoco, México", en Revista de Geografía Agrícola, 57 (jul.-dic. 2016), pp. 158-163.

Isaksen Leonard, Karen, Making Ethnic Choices: California's PunjabiMexican Americans, Filadelfia, Temple University Press, 1992.

JeIFets, Victor y Lazar JeIfETs, “La alianza que terminó en ruptura”, en IllaDES (coord.), 2017, pp. 72-95.

Kent Carrasco, Daniel, “M. N. Roy en México: cosmopolitismo intelectual y contingencia política en la creación del PCM", en IlLAdes (coord.), 2017, pp. 37-71.

Kent Carrasco, Daniel, "The Breath of Revolution: Indian Anticolonial Radicals in the United States and the Mexican Revolution" [en prensa].

Kent Carrasco, Daniel, “Jayaprakash Narayan and lok niti: socialism, Gandhism and political cultures of protest in xx Century India”, tesis de doctorado, Londres, King’s College, 2016.

Khankhoje, Pandurang, "Some factors which influence the water requirements of plants", en Journal of the American Society of Agronomy, 6: 1 (ene.feb. 1914), pp. 1-23. 
Khankhoje, Pandurang, "Nuevas variedades de maíz", en Boletín de Investigación. Estación Experimental Agricola, Escuela Nacional de Agricultura, 1 (1930), pp. 5-14.

Khankhoje, Pandurang “El frijol soya. Glycine Hispida. Max”, en El Campesino, 1: 7 (mar. 1937), pp. 14-15.

Khankhoje, Pandurang, “Escuelas Libres de Agricultura del Estado de Veracruz. Depto. de Ingeniería Agrícola de la Liga de Comunidades Agrarias del Estado de Veracruz”, en Revista de Geografía Agrícola, 57 (jul.-dic. 2016), pp. 187-198.

Leal, Claudia, José Augusto Padua y John Soluri (coords.), "New Environmental Histories of Latin America and the Caribbean", en RCC Perspectives; 7 (2013), pp. 59-65.

Lewis, Daniel, Iron Horse Imperialism: The Southern Pacific of Mexico, 18801951, Tucson, University of Arizona Press, 2007.

Mangelsdorf, P. C. y R. G. Reeves, The Origins of Indian Corn and its Relatives, College Station, Texas, Texas Agricultural Experiment Station, 1939.

Manjapra, Kris, "Knowledgeable Internationalism and the Swadeshi Movement, 1903-1921”, en Economic and Political Weekly, 47: 42 (20 oct. 2012), pp. 53-62.

Matchetт, Karin Elizabeth, "Untold Innovation: Scientific Practice and Corn Improvement in Mexico. 1935-1965”, tesis de doctorado, Minnesota, University of Minnesota, 2002.

Méndez Rojas, Diana Alejandra, "El Programa Cooperativo Centroamericano para el Mejoramiento del Maíz: una historia transnacional de la revolución verde desde Costa Rica y Guatemala, 1954-1963”, tesis de maestría en historia moderna y contemporánea, México, Instituto de Investigaciones Dr. José María Luis Mora, 2018.

Mishra, Pankaj, De las ruinas de los imperios. La rebelión contra Occidente y la metamorfosis de Asia, Barcelona, Galaxia Gutenberg, 2014.

Naoroji, Dadabhai, Poverty of India, Londres, Vincent Brooks, Day and son, 1878.

Olea-Franco, Adolfo, "One century of higher agricultural education and research in Mexico (1850s-1960s), with a preliminary survey on the same 
subjects in the United States", tesis de doctorado en historia de la ciencia, Harvard, Harvard University, 2001.

Olsson, Tore C., Agrarian Crossings: Reformers and the Remaking of the US and Mexican Countryside, Princeton, Princeton University Press, 2017.

Palacios, Guillermo, La pluma y el arado. Los intelectuales pedagógos y la construcción sociocultural del "problema campesino" en México, 1931-1934, México, El Colegio de México, Centro de Investigación y Docencia Económicas, 1999.

Perkins, John H., Geopolitics and the Green Revolution. Wheat, Genes, and the Cold War, Nueva York, Oxford University Press, 1997.

Plowman, Erin Matthew, "The British Intelligence Station in San Francisco during the First World War”, en Journal of Intelligence History, 12: 1 (2013), pp. 1-20.

Ramírez Zavala, Ana Luz, "La justificación higiénico-sanitaria en la campaña antichina, 1924-1932", en Letras Históricas, 12 (primavera-verano 2016), pp. 159-183.

Ramnath, Maia, Haj to Utopia. How the Ghadar Movement Charted Global Radicalism and Attempted to Overthrow the British Empire, Berkeley y Los Angeles, University of California Press, 2011.

Reynoso, Jaime Irving, El agrarismo radical en México en la década de 1920: Úrsulo Galván, Primo Tapia y José Guadalupe Rodríguez (una biografía politica), México, Instituto Nacional de Estudios Históricos de las Revoluciones de México, 2009.

Rivas SADA, Eva, "Cambio tecnológico, dinámica regional y reconversión productiva en el norte de México: la Comarca Lagunera 1925-1975”, tesis de doctorado, Madrid, Universidad Complutense, 2011.

Roy, Basanta Koomar, "Self-support in American Universities", en Bulletin of the Hindusthan Association of U.S.A., 1 (ago. 1913).

SARKar, Sumit, The Swadeshi Movement in Bengal, 1903-1908, Delhi, People’s Publishing House, 1973.

Sawhney, Savitri, I Shall Never Ask for Pardon. A Memoir of Pandurang Khankhoje, Delhi, Penguin Books, 2005. 
Sonnenfeld, D. “Mexico's 'green revolution', 1940-1980: Towards an environmental history”, en Environmental History Review, 16 (1992), pp. 28-52.

Soto Laveaga, Gabriela, "Largo dislocare: connecting microhistories to remap and recenter histories of science", en History and Technology, 34: 1 (2018), pp. 21-30.

SPenser, Daniela, Stumbling Its Way through Mexico: The Early Years of the Communist International, Tuscaloosa, University of Alabama Press, 2011.

Stakman, E. C., R. Bradfield y P. C. Mangelsdorf, Campaigns against Hunger, Cambridge, Mass., The Belknap Press of Harvard University, 1967.

True, Alfred Charles, A History of Agricultural Experimentation and Research in the United States, 1607-1925, Washington, D.C., Government Printing Office, 1937.

Wilkinson, Xenia Vunovic, “Tapping the Amazon from Victory: Brazil's 'Battle for Rubber' of World War II”, tesis de doctorado en historia, Washington, Georgetown University, 2009.

YanKelevich, Pablo, "Mexicanos por naturalización en la primera mitad del siglo xx. Un acercamiento cuantitativo", en Historia Mexicana, LXIv: 4 (256) (abr.-jun. 2015), pp. 1729-1805.

Zimmer, Kenyon, Immigrants against the State. Yiddish and Italian Anarchism in America, Urbana y Chicago, Illinois State University Press, 2015. 
